\title{
Inclusive Aspects of Higher Artistic Education: Experimental Performance by Hearing and Deaf Actors
}

\author{
Natalya Filatova ${ }^{1, *}$ Igor Vostrov $^{1, \mathrm{a}}$ Anna Kostina ${ }^{1, \mathrm{~b}}$ Rushan Iksanov $^{1, \mathrm{c}}$ \\ ${ }^{1}$ Russian State Specialized Academy of Arts, Moscow, Russia \\ ${ }^{a}$ Email: gsiivostr@mail.ru \\ ${ }^{b}$ Email: kostochka13@yandex.ru \\ cEmail:ixanov@hotmail.com \\ "Corresponding author. Email: dapertutto-na@yandex.ru
}

\begin{abstract}
The subject of the present research is the final stage of higher theatre education, namely, the process of staging an inclusive graduation performance by a group of deaf and hearing actors who use sign language and spoken language and interact as full stage partners. The article presents the analysis of some features of Russian sign language, its differences from cued speech, the process of collective translation of a drama text into the Russian sign language, the search for its visual and artistic expression on stage, and the audience's perception of performance in sign language. The authors focus on encouraging creative collaboration between actors during rehearsals and stage performance of Eugène Labiche's vaudeville A Slap in the Farce (La Main Leste) and justifying the decision about performers using different languages. In addition, they give examples of individual artistic devices used in the performance for the most expressive interaction of deaf and hearing actors.
\end{abstract}

Keywords: Higher education for deaf actors, Specialized Academy of Arts, Inclusive performance, Hearing and deaf actors, Artistic sign language, Direct and indirect inclusion, Perception of a performance by the audience.

\section{INTRODUCTION}

Performances by deaf actors given in sign language are not uncommon on modern stage. Each of them can be considered inclusive, as it is not only deaf actors who take part in their production but also actors and theatre services that cannot do without hearing. This article is about full creative inclusion that became the driving force behind the production of the vaudeville performance by students of two different programmes of study at the theatre department of the Russian State Specialized Academy of Arts.

Apart from the Mimics and Gesture Theatre of Moscow, which has been staging various performances in sign language for more than half a century, in recent years there have appeared new professional and amateur theatre groups. One of the new, but already successful ones is the Nedoslov theatre project, which was created by teachers of the theatre department of the Russian State Specialized Academy of Arts almost two decades ago, and has gained popularity among the audience in Russia and near and far abroad. All actors at Nedoslov are former graduates of the Russian State Specialized Academy of Arts of different years.

The theatre hall of the academy is usually full house. Alongside with deaf members of the audience, there are always those who perceive spoken language and have no grasp of sign language. In fact, not knowing it does not prevent the audience from understanding a sign language performance. The acting is so captivating that an ordinary member of the audience takes no notice of all characters speaking in one or two voices (as a rule, all male parts are voiced by one male voice actor (interpreter) and all female ones - by one female interpreter). Sometimes one interpreter is voicing all characters, which usually happens in student performances. 
A performance by deaf actors voiced by interpreters is usually as follows: while actors are performing on stage, two voice actors-interpreters are in the theatre auditorium, at a desk (sometimes with a reading lamp) right in front of the stage, looking at the stage, reading the lines, and trying to synchronize with the characters. They are not full participants in a play, rather people "from the outside", although there have been examples of such an accurate voicing when it seems that the actors speak with their voices rather than signs. Thus, the audience gets a full image of a character with a voice - the effect we all know from dubbed films.

It is rare, but in some cases, the number of voice actors in a sign language performance by a deaf theatre group can reach four people. Thus, a dialogue between two male characters is voiced by two male actors-interpreters, which is done to provide a more complete sound image for the hearing audience. The same can apply to women's dialogues. However, theatre groups seldom have the opportunity to employ that many professional voice actors-interpreters. In addition, more and more often, theatres, including the Mimics and Gesture Theatre of Moscow, produce plastic performances that do not require voicing. Unfortunately, in such performances, the psychological depth behind living the part is sometimes substituted by the brightness of a plastic image.

And yet, the audience is considerably attracted by performances that reveal the psychological depth, the drama of characters' relationships, their experiences, and the process of making difficult choices. To satisfy this need, the hearing audience can visit any good theatre, whereas for the deaf audience the only option is a sign language theatre. As there is also the heading audience who perceive a play through voice-over by actors-interpreters, a performance by deaf actors should be understandable and engaging to all the audience, either hearing or deaf.

\section{THE CHOICE OF A PLAY FOR THE GRADUATION PERFORMANCE AND ITS CONCEPTION}

Forming an inclusive group of students of different years for the performance, we were looking for opportunities to diversify performances by deaf students and, most importantly, to encourage creative collaboration of hearing and deaf actors and connect the spoken Russian language and Russian sign language, since the creative nature of an actor does not depend on the language and expressive means used in a performance. The pedagogical search was guided by the main rule of working with students choosing the best of all options to unlock the potential of novice actors, to develop their creative skills, and provide opportunities for professional growth. We always keep in mind Evgeny Vakhtangov's message about the main task of a theatre school - to educate actors, which implies personality development and unlocking the creative potential of each future theatre artist. It is exactly an actor's professional education that Vakhtangov, the creator of the most outstanding theatre productions, always considered the key to a successful performance. This idea is discussed in many of his diary entries, one of which is as follows: "An actor's education should consist in enriching their subconsciousness with diverse abilities: to be free, concentrated, serious, effective on stage, artistic, active, expressive, observant, quick to adapt, etc. There is no end to this list of abilities ... The main mistake theatre schools make is that they undertake to teach, while it is necessary to educate." [1] Starting this inclusive project, we believed that each participant would benefit creatively from it.

The methods of training deaf actors is a young science; its development in Russia started only 30 years ago when a specialized university was established. The first collection of articles devoted to the problems of training deaf actors was published in 1990. [2] Undoubtedly, teaching deaf actors has certain peculiarities. On the other hand, in terms of psychology, all people's lives are subordinated to the same laws, no matter whether a person is hearing or not, whether they have good eyesight or are blind.

For a graduation performance of the programme of study for deaf students, Eugène Labiche's vaudeville A Slap in the Farce was chosen. [3] For novice actors, performing comedy is both a challenge and an excellent professional training. A plot of a vaudeville always implies a variety of misunderstandings, and A Slap in the Farce is no exception. A tiny hat atelier, Monsieur Legrainard - its owner, his wife, and their marriageable daughter. The other day in an omnibus, some impudent fellow dared to run his hand over the lady's leg and whisper gentle words to her. The lady slapped him in the face (such was her communication style), and proudly got off the 
omnibus, having left her purse there with some money in it. When she leaves for the lost and found office, a handsome young artist brings her purse and demands compensation for the slap in the face he did not deserve. It appears he had a dog under the bench in the omnibus and bent over to stroke it. Suddenly, the lights went off, and he received a resounding slap from the lady sitting next to him. When he comes, the owner's daughter takes him for the fiancé promised by the parents ... and they fall in love with each other. What follows is a refusal, a duel, another slap in the face, an idea that turns the poor artist into a rich man in the parents' eyes, happy end, and singing verses.

In deaf theatre, there are moments of particular difficulty when characters need, for example, to sing. Such scenes are usually either eliminated or pre-recorded, but as a rule, recorded sign-singing seems out of place in a performance (it does not refer to concert sign-singing performances, in which it is initially clear that a famous song has been translated into sign language). Meanwhile, a comedy-vaudeville cannot do without music, dance, and songs (light verses, romances, etc.). Does it pose a problem? It sure does. Nevertheless, the teachers who started working on the vaudeville set the task for themselves and the students to introduce live singing in the performance, that is, sign-singing accompanied by live voices. Thus, the characters would sing (what a vaudeville without verses!), but not to a pre-recorded tape.

That academic year, the final year deaf students of the theatre department closely communicated with hearing pre-graduation actors. The atmosphere at the theatre department of the Academy is generally very friendly: students of different years are engaged in presentation of individual works; junior students always assist final year students in their performances: they prepare the stage and costumes, put on the sets, and are on standby in the auditorium. The students of the two programmes of study mentioned above interacted even more closely than that: the speaking students easily learned the basics of sign language, so everyday communication was not a problem. Thus, one task was completed - students willing to participate in the performance came forward. Then, each character of the performance was to get not just an individual interpreter whose voice would be heard, but a partner, a participant in the performance, and a link between the characters and the audience.

\section{COLLABORATIVE TRANSLATION OF THE PLAY INTO SIGN LANGUAGE}

An integral component of working with deaf actors is a collective translation of a text into sign language. Without such translation, it is impossible to move on, to understand the roles, the meaning of the heroes' actions and their relationships with partners, and in general to give a performance. The collective translation of literary texts or drama into sign language is a separate and very complex topic, which in the present article is only touched upon to the extent necessary to cover the main topic production of an experimental inclusive performance with participation of hearing and deaf actors.

Translating verbal concepts into visual sign language is rather challenging. In order to provide quality translation that would accurately convey meaning, it is essential to attract a professional sign language interpreter, a teacher-director, and, of course, actors. Not every person having learned sign language can participate in rehearsals and translate complex scenes from a verbal language into a visual one. The complexity of conveying the meaning of abstract concepts and synonymy of signs make it more difficult to understand the context of a particular scene or dialogue.

Additionally, there exist two different approaches to translating and creating a sign language speech construct. The first one is a literal translation of a verbal sentence, or cued speech, the other one is a translation into Russian sign language. According to G.L. Zaytseva, the renowned researcher of sign language, the Russian sign language is "a kind of linguistic system having its own vocabulary, grammar, and the logic of constructing a sentence and conveying the meaning expressed by signs" [4]. G.L. Zaytseva studied the functioning of sign language in communication of the deaf, the stylistics of the Russian sign language, and the differences between sign language and cued speech.

In the performance, the characters spoke in two ways simultaneously for a better understanding of the audience — with signs and articulatorily (soundlessly). Therefore, during rehearsals, it was necessary to reach a balance between these two lines. However, the text of a play is created to be perceived verbally, and this is where a question arises: how to translate - into cued speech for the convenience of the hearing audience or into sign 
language for the convenience of deaf actors and the deaf audience? The problem is not as simple as it may seem. On the one hand, translated lines should be convenient for the actors to pronounce, whereas it is also important to think about the deaf audience who want to see and understand everything. The key problem is reaching a balance of signs and articulation in actors who think in Russian sign language, but in the performance need to speak two languages simultaneously — sign and sounding languages.

The main language of a deaf actor (and a character of the play) is sign language, so the need to use two languages often poses an obstacle for novice actors. When rehearsing, teachers sometimes ask student actors to turn off their hearing aids, close their mouths, not to articulate, but act, thinking and speaking only using signs, and only later, when the idea of a scene is clear, should they be allowed to involve articulation. Therefore, when translating a play into sign language, the main attention is paid to the possibility of expressing the text with signs. Articulation is adjusted to signs; sometimes they do not coincide, or words are articulated selectively (only the main ones or those requiring situational explanation). Thus, a deaf actor had two simultaneous, but not identical lines: signs and articulation. For example, in the verses sung at the beginning of the vaudeville, there was the following line: "Montmartre is all illuminated". In sign speech, it was "street + street-lamps" in the corresponding rhythm, and simultaneously everyone articulated "Montmartre is all illuminated".

Analysing the text and the logic behind the characters' actions, we translated their lines into sign language and created the sign language constructs of the performance. Students made notes in their notebooks, each sketching translation scheme in their own way. This first stage of working on this performance was no different from working on any other dramatic material. In the translation of verses, we aimed at preserving their rhythmic pattern, as well as the rhythmic pattern of the selected music material. As a result, in the process of collective translation, some cuts and adjustments were introduced to the text of the vaudeville, so that performing in sign language, along with articulating words would be comfortable for the performers and would not affect the meaning of a scene.

Another difficulty was the perception of the text by the audience. The hearing audience better perceives cued speech, when the construction of a sentence is familiar to the ear. For instance, it is easy for them to understand the following sentence: "Put red apples in the big basket". If there is such a sentence in the play, for the hearing audience it is better to perceive it articulated in sign language as is, in the direct word order: "Put red apples in the big basket". They hear the voice of the interpreter and see the actor articulating the same words, so there is no perception dissonance. However, for the deaf who communicate using Russian sign language, it is difficult to understand first the attributes "red" or "big", and then the nouns "apples" or "basket". According to G.L. Zaytseva, in everyday communication, when interlocutors are near each other and see each other well, the sequence of words in Russian sign speech can be different. The task of translating drama into sign language with students can be approached differently and individually, depending on how well they know the language, their residual hearing, and much more. The issues of translation, stage artistic sign language, translation for a particular performer, creating and consolidating constructs of the sign text of a part and a play itself have long been a subject of discussion for teachers, directors, and sign language interpreters. [5] [6] [7]

In the practice of creating stage artistic language, it is necessary to verify signs very carefully: the audience is far from the stage, and they have no chance to interrupt and ask for clarification. Therefore, the logic of constructing sentences in the sign language should be understandable for the audience: first, subjects, then predicates or attributes. In Russian sign language, such a sentence will be approximately as follows: "the basket is big, red apples put"; articulatorily, it can be expressed in the following way: "in the big basket put the red apples". Most often, such adjustments to word order are made when characters address each other, for example: "Where are you going, darling?" is changed to "Darling, where are you going?" (when Monsieur Legrainard asks his wife in the first scene of the vaudeville).

Moreover, sign language is characterized by its special expressiveness. When Monsieur Legrainard is faced with a difficult choice - to fight a duel with a young stranger or to let him kiss his wife, he says "duel" and "kiss" in sign language. "Duel" is two index fingers crossed, and "kiss" is a crossed juncture of index and middle fingers of both hands. When considering what choice to make, he keeps changing these two signs, which do not require 
translation and are clear to both the deaf and the hearing. In the end, he chooses a "kiss"...

\section{ACTORS' INTERACTION DURING REHEARSALS AND STAGE PERFORMANCE}

Student performances are usually voiced by professional sign language interpreters who do not recite the learned lines of a part, but simultaneously interpret what is being said. Due to this traditional way of voicing a performance, the teachers' plans to introduce voicing by singing students of the variety arts programme of study, met colleagues' criticism. They claimed that since these students did not know the sign language, they would not be able to synchronize with the performers' signs. Nevertheless, the teachers decided to rise up for the challenge, with the intention of making the singing students full-fledged participants in the performance.

At first, the verses were rehearsed by hearing and deaf performers separately. With the latter, it first was with beating out time, then to the piano. The next stage was joint rehearsals and attempts to synchronize. We tried to ensure that the singing voices matched the context, and the performers' individuality, organically accompanied the performance and were consonant with the voice of the interpreter voicing the entire text. Thus, two students of a different programme of study joined the performance, having become "people of the theatre". They were wearing theatrical costumes, took part in dances, and performed vocal items.

It should be mentioned that although the performed extracts of the vaudeville received a warm welcome at the chair, the very idea of participation of "two singing heads" was met with scepticism, and the teachers' plans to extend the application of this method of voicing a sign language performance did not find support. Then, the academic year was over, students went on summer holidays, and the teachers continued to reflect on how to introduce the "second cast" of characters into the performance.

Vaudeville as a genre implies frequent direct appeal of the characters of the performance to the audience. Anything that is told in secret is addressed to the audience; apart lines seem to shorten the distance between the actors and the audience as if they find themselves playing the same game. Our "speaking cast" was expected to bring the audience even closer to what was happening on stage. In the playbill, two actors were assigned to each part. They appeared on stage together, their dresses were identical, and when the opening verses were performed, it was difficult to tell one from the other. The sign language actors acted in the foreground so that the deaf audience could accurately perceive the lines, while the singing performers were in the background. Only after that, right in front of the audience, they were separated: one put on the historical costume, whereas the other one, blowing a partner a kiss, went downstage.

The "voices" were placed downstage, at a small desk to the right of the audience. In such a mise-enscene, they could communicate with the accompanier, the audience, and the actors. Their performing task was not just voicing, and not just a full dubbing, but also participation in some scenes. The lines, articulated and expressed in sign language, had to be accurately voiced, with the same mood, emotions, and direction. Additionally, they gave silent signals (visible bells that are usually used in homes of the deaf), conducted musical performances, came into play, sometimes introducing amusing intricacies into what was happening. They sang, danced, and did everything that their characters had to do on stage - they acted in a play.

Having joined the rehearsal process, the new performers encountered many questions: whether they should act along with characters, whether they provide voiceover only, and who they are in the performance, actors or characters. It was a completely new experience for them. At that moment, we, the teachers did not have answers to all those questions, since it also was our first experience of the kind.

After that, the "voices" started working on the text, already translated and edited for sign speech. One scene was eliminated, another one was added, many adjustments were made, and rehearsals were ahead. We wanted to achieve the unity of the sign

and sounding speech in the performance. The "voices" had to learn to synchronize with their partners, in articulation, to convey the same emotions, and send the same message. The work was not only about voicing but about psychophysics, in general. They had to play the part and be thoroughly engaged in a scene but without overacting the main performers or attracting too much. Attending rehearsals, participating in scene analysis, understanding acting and signs, joint rehearsals with the choreographer and accompanier 
- for them, it was comprehensive academic work. Editing the translated text continued, it was necessary to achieve accurate synchronization between sign speech and its voicing that would be presented by two performers at once: for the deaf and the hearing audience.

To achieve interaction between partners, it was important to understand the genre, tempo-rhythm, and mood of a vaudeville. All this cannot be learned just by reciting the text. Therefore, students eagerly participated in any scene. There were rehearsals when the "voices" were given freedom and performed the vaudeville themselves. Some of the moves discovered in these rehearsals were later included in the performance. Costume design for "voices" was also an issue, which was resolved due to professional theatre artists.
To illustrate how the two casts of actors interact in the performance, several scenes can be mentioned. For example, in the very first scene, the father is feeling dizzy, and the two wives pass by simultaneously, one putting on a hat, the other one taking an umbrella.

In another scene, the father, not willing to continue a conversation with his daughter about the fiancé, sends her to the atelier, but she does not listen, sings verses, and tries to escape. Supporting the angry father, his voice partner sings with him, and so does the daughter's one. The "daughters" run away, and the "fathers" catch the "wrong" children, get utterly confused, and together complain bitterly about the heavy burden of fathers of adult daughters. They use sign speech, the audience hears well, understands what is happening and finds it comical. ("Figure 1")

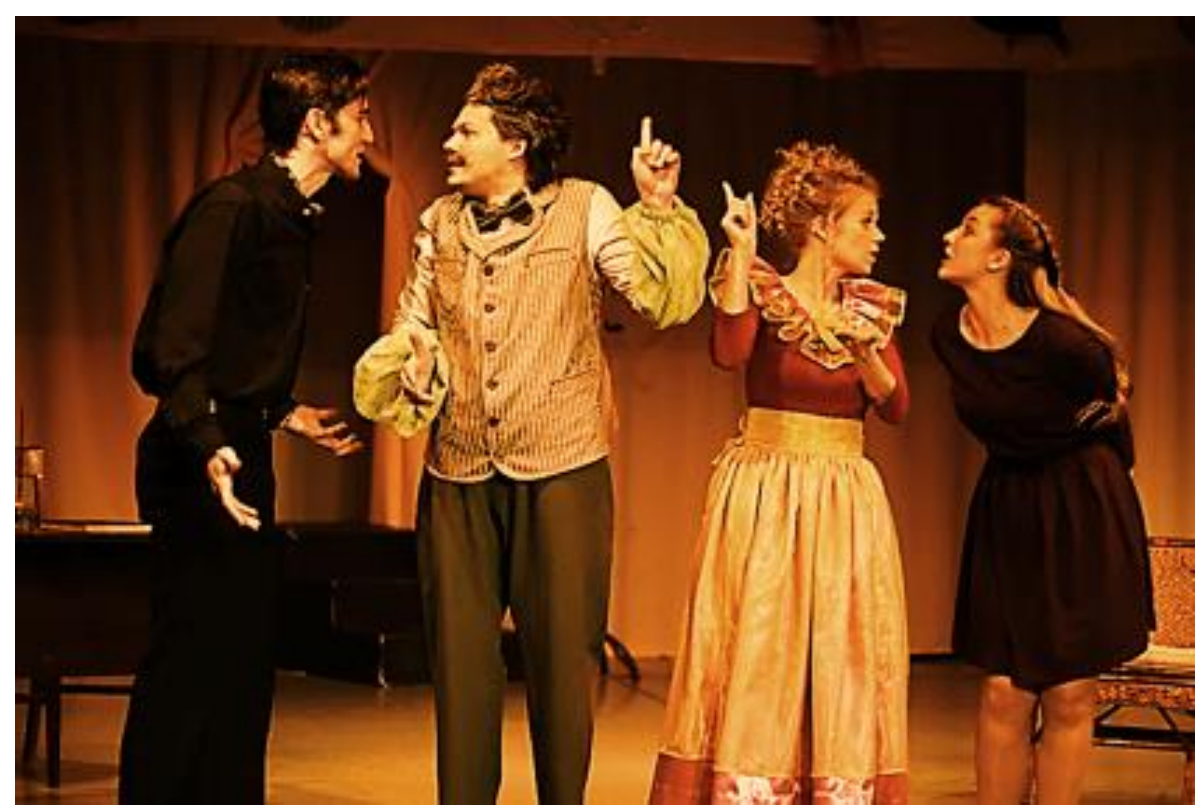

Figure 1 Photo from the performance: two "fathers" and two "daughters" actively communicating.

Another scene is as follows: a terrifying moment — a duel between the father and his daughter's fiancé is about to take place. Suddenly, the young artist realizes that he only can use a brush, and has never fought in duels with swords. He shouts for help and asks the audience to show him a few strokes (as a rule, audience members end in talk and do not dare to go on stage). Then his "voice" comes to his rescue and shows how to strike at an imaginary opponent with a sword. Of course, Eugène Labiche did not have this scene, it was invented during rehearsals. Moreover, E. Labiche could hardly think that someday his vaudeville would be staged in such an unusual way.
The recording of A Slap in the Farce can be found on the website of the Academy. [8]

\section{CONCLUSION}

Firstly, the inclusive "multilingual" team working on the performance was friendly and efficient; during rehearsals, communication in sign language became easier and more extensive: the performers managed to understand each other on stage and behind the scenes. All the participants in the performance gained a unique partnership experience.

Secondly, the performance was understood and received a warm welcome from the audience. The 
deaf thoroughly enjoyed the performance, perhaps even more than the hearing. Each appearance and precise synchronization in action with the "second character" received loud applause. The performance was a success at three festivals.

Thirdly, this fully creative, inclusive theatre work has potential. We hope that there will be many more inclusive performances of different genres for actors to participate in and for the audience to enjoy. Establishing psychological and emotional contact allows overcoming language barriers. It is necessary to select suitable drama, look for theatre groups ready for such experiments, and to draw attention to the problem of the sociocultural isolation of the deaf. There are no limits to creative inclusion, and the authors of the present article will definitely continue this creative work.

\section{AUTHORS' CONTRIBUTIONS}

Natalya Filatova and Igor Vostrov produced, developed and implemented the idea of staging an inclusive performance. Anna Kostina and Rushan Iksanov took part in the production of the play, developing plastic stage movements of characters. Natalya Filatova prepared the text of the present article. All authors participated in the discussion of the results of the research and introduced corrections.

\section{ACKNOWLEDGMENTS}

The authors are profoundly grateful to Sofya N. Babkina and Varvara E. Romashkina, sign language interpreters, who participated in the rehearsals and collective translation of the play. It is due to their professionalism and knowledge of the peculiarities and expressive means of the stage sign language that all characters' scripts were translated with the account of the actors' individuality and the genre of the performance.

\section{REFERENCES}

[1] Evgeny Vakhtangov. Ed. by L. D. Vendrovskaya, G.P. Kaptereva. Moscow, 1984. p. 276.

[2] Deaf theatre and theatre for the deaf (Contradictions, problems, and searches). Collection of articles. Ed. by A.V. Mekke. Leningrad, 1990.

[3] Eugène Labiche. A slap in the farce. Translated from French into Russian by A. N.
Fari. Ed. by A. K. Dzhivelegova; Poem translation by T.L. Schepkina-Kupernik. Moscow, Leningrad, 1945. 139 p.

[4] Zaytseva G. L. Sign speech. Dactylology: A textbook for higher education students. Moscow, VLADOS, 2004. P. 33.

[5] Vostrov I. M., Kameneva V. P., Romashkina V. E. From street language to artistic sign language. Art education and science. Moscow, 2015. No. 1 (2). Pp. 50-54.

[6] Theatre education of deaf and hard of hearing actors: Study guide. E.O. Bagrova, E.O. Bidnaya, I.M. Vostrov, A.V. Pichugina, N.A. Filatova. Ed. by N.A. Filatova. Moscow, 2018. 154 p.

[7] Filatova N. A. Verbal constructs of the sign language text of a part: the algorithm of work. Proceedings of the III International conference Art, Design and Modern Education (Moscow, May 29-30, 2017). Moscow, 2017. Pp. 293304.

[8] Video recording of the graduation performance A Slap in the Farce by Eugène Labiche. Available at: http://rgsai.ru/component/yendifvideoshare/vi deo/185-23-06-2019-poshchechina 